\section{Pedagogia Hospitalar: Uma contribuição saudável no processo de alfabetização de crianças hospitalizadas}

\author{
Lidiane Aragão Santana* \\ Francy Sousa Rabelo** \\ Joelma Reis Correia ${ }^{* * *}$
}

\section{Resumo}

O presente artigo tem intuito de analisar a contribuição da Pedagogia Hospitalar no processo de alfabetização de crianças hospitalizadas no Hospital Materno Infantil, sendo que o escopo do estudo focaliza a alfabetização alicerçada nos estudos de Emilia Ferreiro e Ana Teberosky, dentre outros. Discute-se o atendimento pedagógico hospitalar como uma modalidade educativa não formal que visa valorizar o processo de alfabetização consolidando o direito da criança hospitalizada. Utiliza-se como enfoque metodológico, a pesquisa qualitativa de cunho exploratório no Hospital Universitário Materno Infantil, tendo como sujeitos da pesquisa, a pedagoga do hospital e alunas voluntárias do projeto de extensão "Estudar uma ação saudável". Conclui-se que a Pedagogia Hospitalar contribui significativamente na promoção da continuidade do processo de alfabetização das crianças hospitalizadas, respeitando seus limites e propiciando seu retorno à escola sem fragmentação em seu desenvolvimento de ser cognoscente.

Palavras-chave: Alfabetização. Educação Não Formal. Pedagogia Hospitalar.

\footnotetext{
* Graduada em Pedagogia pela UFMA, Professora Rede Municipal de Ensino de São Luis, Voluntária do Projeto de Extensão Estudar, uma ação Saudável da UFMA - lidianesantana.pe@gmail.com.

** Professora do Departamento de Educação I e Coordenadora do Projeto Estudar, uma ação saudável da UFMA- franrabelo@hotmail.com

*** Doutora em Educação pela UNESP e Professora do Departamento de Educação I da UFMA, Atua na área de Leitura e Escrita. - joelmareis1970@hotmail.com com.
}

\section{Hospital Pedagogy: A healthy contribution in the literacy process of children hospitalized}

\section{Abstract}

The present article intends to analyze the contribution of the Hospital Pedagogy in the literacy process of hospitalized children at the Hospital Materno Infantil. It approaches the acquisition of writing in the conceptional way, constructivist and historic-cultural, with the scope of the study focused on literacy in the constructivist perspective rooted in the studies of Emilia Ferreiro and Ana Teberosky. The role of the pedagogic hospital care has been discussed as a non-formal educational method that aims to enhance the literacy process by consolidating the hospitalized children's rights . It employs the methodological approach, the qualitative exploratory research at the University Hospital Moterno Infantil, holding as research subjects, the hospital's pedagogue and volunteer students from the extension project " "Estudar uma ação saudável " (Studying a healthy activity"). It has been concluded that the Hospital Pedagogy significantly contributes to promoting the continuity of the literacy process of hospitalized children, respecting their limitations and allowing their return to school without the fragmentation of their cognitive development.

Key-words: literacy; Non-Formal Education, Hospital Pedagogy. 


\section{Introdução}

O presente estudo aborda duas categorias: a alfabetização e a Pedagogia Hospitalar que se entrelaçam durante processo de alfabetização de crianças hospitalizadas.

Segundo os estudos de Emilia Ferreiro Ana Teberosky, esse processo inicia desde muito cedo, antes mesmo da criança adentrar na escola. Baseada na teoria de Jean Piaget, as referidas autoras realizaram um trabalho que desmistificou as abordagens tradicionais de educação que compreendiam a aquisição da escrita como uma ação cumulativa. Nessa perspectiva, a criança era uma tábula rasa, logo não pensava. Então, cabia ao professor depositar conhecimentos na mente da mesma.

Essa concepção de alfabetização foi contestada após a teoria da psicogênese da língua escrita, pautada nos estudos de Jean Piaget. As autoras Emilia Ferreiro e Ana Teberosky investigaram a gênese da escrita a partir da metodologia usada pelo referido teórico. Somente na década de oitenta ocorreu a divulgação dessas ideias no Brasil. Então, tivemos uma mudança de paradigma. A criança se torna o sujeito da aprendizagem. Ela é vista como um ser ativo no sentido de pensar, refletir, levantar hipóteses e construir conhecimento. Além disso, esse sujeito possui conhecimentos prévios que precisam ser valorizados na sua vida escolar.

Diante deste contexto, já não podemos mais pensar no espaço escolar como unanimidade para promover a alfabetização. Pois, no ambiente hospitalar também pode ocorrer a aquisição da linguagem escrita. Embora, ainda seja visto como um espaço frio que configura dor e sofrimento. Para a criança, esse ambiente torna-se mais temeroso, pois quando necessita ser internada, há uma ruptura tanto na sua rotina familiar, quanto escolar e consequentemente prejuízo no seu desenvolvimento cognitivo, em virtude da sua ausência na escola formal. Portanto, essa concepção de ambiente hospitalar está se transformando, paulatinamente e a educação não formal está contribuindo para essa mudança. Para isso, conta com a Pedagogia Hospitalar para realizar o atendimento pedagógico em âmbito hospitalar. Essa nova perspectiva tem o intuito de propiciar aos escolares hospitalizados, o contínuo contato com o conhecimento, a brincadeira, a socialização, permitindo a interação com o mundo, mesmo não estando no seu ambiente social.

Diante desse contexto, analisamos a contribuição da pedagogia hospitalar no processo de alfabetização de crianças hospitalizadas, para isso observamos como os autores responsáveis pelo atendimento pedagógico no Hospital Materno Infantil têm trabalhado para dar continuidade a esse processo na referida instituição.

\section{Alfabetização Na Perspectiva Construtivista}

O processo de alfabetização na vida do sujeito é decisivo para desenvolver habilidades na leitura e na escrita. É o momento de descobrir o mundo da linguagem escrita e, concomitante, o prazer de compreender e apropriar-se desse mundo. Todavia, não é uma caminhada fácil principalmente quando acreditamos que a alfabetização consiste na aprendizagem cumulativa e que o sujeito não é ativo nesse processo.

A difusão da concepção construtivista de alfabetização, baseada nos estudos de Emilia Ferreiro e Ana Teberosky, fundamentada na teoria de Piaget, vem rompendo, paulatinamente, o modo de conceber como a criança aprende a ler e a escrever, apesar de Piaget não ter tratado da gênese da leitura e da escrita.

$\mathrm{Na}$ visão das referidas autoras, a língua escrita é um objeto de conhecimento e o sujeito da aprendizagem, um sujeito cognoscente, ou seja, é

[...] o sujeito que busca adquirir conhecimento, o sujeito que a teoria de Piaget nos ensinou a descobri. O que quer dizer isto? $\mathrm{O}$ sujeito que conhecemos através da teoria de Piaget é um sujeito que procura ativamente compreender o mundo que o rodeia e trata de resolver as interrogações que este mudo provoca. (FERREIRO; TEBEROSKY, 1985, p.26)

Dessa forma, para Ferreiro e Teberosky (1985, p.29), a criança diante da escrita é considerada um sujeito ativo, porque "analisa, ordena, exclui, compara, cria hipóteses." 
Este modo de conceber a criança que aprende provoca uma revolução na alfabetização, fundamentada no modelo construtivista de ensino.

Teberosky e Colomer (2003) destacam alguns princípios desse modelo de ensino, importantes tanto na alfabetização quanto em outras áreas de ensino. $O$ primeiro é o teórico, ou seja, são as estratégias que o professor vai utilizar para construir novas aprendizagens de acordo com os conhecimentos prévios dos alunos. O segundo, diz respeito a apresentar situações-problema. Essas situações-problemas exigem esforços dos alunos, pois estes vão construindo respostas plausíveis durante o processo de aprendizagem. $O$ terceiro consiste em dar o suporte necessário para o aluno proceder através de perguntas que possibilitem a sua reflexão sobre o conteúdo a ser construído. Vale lembrar, que o docente precisa considerar o que o aluno conhece. $\mathrm{O}$ quarto considera a importância dos agrupamentos para trabalhar atividades com os alunos, visto que essa estratégia gera discussões e, concomitante, o aprendizado. O último concebe o professor como modelo de interpretação e de produção de escrita. Nesse caso, cabe ao professor transmitir para o aluno a função da leitura e da escrita de maneira efetiva, lendo e produzindo textos com as crianças.

Ademais, as autoras destacam a importância do ambiente alfabetizador para as crianças interagirem com os materiais de leitura e escrita. Nessa perspectiva, assinalam Teberosky e Colomer (2003, p. 82): “Um modelo construtivista de ensino e de aprendizagem da linguagem e da alfabetização deve organizar atividades e proporcionar ambientes que incorporem essas duas dimensões.".

As experiências realizadas por Ferreiro e Teberosky sobre a psicogênese da língua escrita configuram as mudanças no processo de alfabetização, ou seja, apresentam propostas e objetivos diferentes da concepção tradicional, dentre eles Ferreiro (2005) destaca: a restituição da língua escrita como objeto social; o acesso à escrita na educação infantil, considerando o nível da criança; interação com a língua escrita nos mais variados contextos; acesso à escrita do nome como ponto importante para a evolução na escrita; não supervalorizar a criança, mas também não se subvalorizar; a correção gráfica e a ortografia são questões que não podem ser analisadas de imediato, ou seja, nos períodos anteriores ao alfabético.

Para Ferreiro (2005, p.19) um dos objetivos mais ausentes na alfabetização "é o de compreender as funções da língua escrita." Quando a criança vive em um ambiente que faz uso constante da escrita, a mesma já conhece a sua função, entretanto, para as crianças que vivem em um ambiente cujo os pais são analfabetos, as múltiplas funções da escrita é desconhecida. Então, cabe a escola proporcionar o envolvimento da criança com a linguagem escrita, oferecendo um ambiente alfabetizador com cantos de leitura e diversos tipos de materiais escritos, inclusive os que estão presentes na casa e na comunidade em que vive a criança.

Segundo a proposta construtivista de alfabetização, não é mais permitido esconder da criança que se encontra na pré-escola o uso funcional da língua escrita, pois as crianças "iniciam o seu aprendizado nos mais variados contextos, porque a escrita faz parte da paisagem urbana e a vida urbana requer continuamente o uso da leitura." (FERREIRO 2001, p, 98). Ou seja, ela está em um ambiente recheado de formas gráficas sejam letras ou números, mas para Ferreiro (2001, p.98) o mais importante é a criança "saber que essas formas gráficas servem para uma atividade especifica que é o ato de ler e que resultam de uma outra atividade também especifica que é o ato de escrever".

Sendo assim, a criança no seu cotidiano recebe informações de objetos portadores ou suportes de textos, de alguém que lê para ela, ou para ter uma informação. Vivenciando essas situações a criança compreende que a função da escrita é de veicular informação, possibilitar a comunicação a distancia, através de cartas, e-mail e, ainda, a leitura torna possível lembrar uma informação que foi esquecida, ou seja, ao ler uma agenda, uma receita, o sujeito se apropria de informação importante para ele naquele momento, que foi possível somente com ato da leitura.

Como já abordamos, a criança vive em um ambiente urbano repleto de portadores e suportes de textos; quando inicia na educação infantil, é importante que ela encontre na escola essa cultura escrita que vivencia no seu 
cotidiano, caso a criança não viva em um ambiente urbano cabe a escola oportunizar o seu contato com essa cultura escrita. Por esse motivo, segundo Teberosky e Colomer (2003, p. 84), "é necessário a interação da criança com esse material na sala de aula, pois "permitem uma primeira iniciação as diversas funções da escrita".

As autoras ainda acrescentam que esse material pode ser usado em diversas atividades, até mesmo pode ser imitado, permitindo a criança, por exemplo, construir um livro de receitas, um jornal, um dicionário e outros. Essa ação de permitir outros materiais escritos não convencionais no ambiente escolar, de acordo com Teberosky e Colomer (2003, p.85) "facilita não apenas a contextualização da aprendizagem, mas favorece um movimento inverso: a participação infantil fora da escola, no mundo da escrita".

Outra estratégia importante na educação infantil é leitura em voz alta de diversos portadores de textos, para a criança se apropriar da linguagem escrita, isto porque,

[...] a leitura em voz alta 'permite associar os signos gráficos com a linguagem e a linguagem com os tipos de textos, ou seja, os gêneros e os suportes materiais sobre os quais eles se apresentam. Mas, além disso, escutar a leitura em voz alta é escutar a linguagem, e isso ajuda a criança a desenvolver sua competência lingüística. (TEBEROSKY; COLOMER, 2003, p. 86, grifo das autoras)

Ademais, o ensino da leitura e da escrita na Educação Infantil ou nos primeiros anos do Ensino Fundamental, baseada na proposta construtivista, tem início antes da criança ler e escrever convencionalmente. Assim, convém questionar de que modo esse processo acontece?

Com relação ao ensino da leitura, é preciso considerar que muitas crianças quando chegam à instituição escolar já trazem alguns conhecimentos prévios que, segundo Miras (1996, p.61), "são os fundamentos da construção dos novos significados." Neste sentido, tais conhecimentos precisam ser considerados pela professora, pois quanto mais relação existir entre o novo conteúdo a ser aprendido e os conhecimentos prévios da criança, mais significativa será a aprendizagem. As crianças levantam hipóteses plausíveis do que pode e do que não pode ser lido.

Para Curto, Morillo, Teixidó (2000, p.46) esta leitura não convencional, precisa de algumas condições, dentre elas: a presença de imagem; o contexto e a situação em que a criança realiza o ato de ler são limitados e precisos, por exemplo, através da chamada com as fichas de nomes as crianças podem ler o próprio nome e também o nome dos colegas; o trabalho com textos já memorizados como músicas, poesias, adivinhações facilitam o reconhecimento e a localização de palavras; a leitura em companhia de um adulto ou colega que possa dar informações necessárias sobre uma palavra. Mesmo ainda não lendo convencionalmente a criança realiza leituras plausíveis, colocando em jogo tudo que sabe sobre a linguagem escrita, pois interpreta e elabora hipóteses.

Ao ler não apenas utilizamos conhecimentos prévios acerca do escrito; se fosse assim, não se produziria aprendizagem ao ler. Requerem-se também estratégias para aprender a partir da leitura. $\mathrm{O}$ ensino das estratégias de leitura compreensiva não pode ser deixado para idades avançadas. Ou se ensinam desde o início da leitura - nos primeiros contatos da criança com textos escritos - ou nos arriscamos a aprovar pessoas que sabem decifrar, mas não utilizam à leitura como meio de aprendizagem, nem de acesso à informação, nem de prazer, etc. (CURTO; MORILLO; TEIXIDÓ, 2000, p.48).

A produção da escrita, segundo os estudos de Emilia Ferreiro (2001), é evolutiva, logo, passa por vários períodos. O primeiro corresponde ao pré-silábico; o segundo, é o silábico, que apresenta algumas particularidades, pois a criança pode analisar sílabas e escrever letras correspondentes aos sons (fonetização), ou pode ocorrer da criança escrever uma letra para cada sílaba, ou, ainda, escrever duas letras para cada sílaba, para a autora no segundo caso parece que a criança não analisou a sílaba. Em consideração a essa oscilação a autora denominou esse período de transição.

Cada momento dessa evolução cria suas próprias zonas de conflito (sem isto não haveria evo- 
lução). Porque o que é preciso entender é que o ápice da teoria silábica pré-anuncia sua própria morte [...], simplesmente porque todo esse trabalho cognitivo, que é feito para entender uma realidade exterior, deve enfrentar finalmente uma escrita alfabética que não corresponde a lógica da teoria silábica. (FERREIRO, 2001, p. 95)

Outro período dessa linha evolutiva é o silábico-alfabético. Neste momento a criança realiza uma análise da silaba, que não é linear, pois nem sempre a criança fará a análise de todas as sílabas, por exemplo, a palavra pato, pode ser escrita do seguinte modo: PTO ou PAO. É relevante acrescentar que, segundo Ferreiro (2001), nesse período a criança pode escrever textos, mas ressalta que os textos curtos são os mais apropriados neste momento. Após esse período a criança encontrar-se na fase alfabética.

Durante esse processo ocorrem os conflitos que vão determinar a reconstrução do conhecimento para um próximo período, desencadeando em erros por parte da criança, no entanto, considerados construtivos, segundo a teoria construtivista, uma vez que são importantes para o professor conhecer o nível da criança para realizar as intervenções necessárias.

Em todo esse processo, a criança vai se apropriando da função social da escrita, e assim passa a compreender por que e para quê precisamos escrever. Diante disso, não cabe mais a visão de uma escrita fragmentada, em que primeiro se aprende a desenhar letras para então entender que a escrita serve para comunicar e expressar idéias, opiniões.

Para a concepção construtivista, aprendemos quando somos capazes de elaborar uma representação pessoal sobre um objeto da realidade ou conteúdo que pretendemos aprender. Essa elaboração implica aproximar-se de tal objeto ou conteúdo com a finalidade de apreendê-lo; não se trata de uma aproximação vazia, a partir do nada, mas a partir das experiências, interesses e conhecimentos prévios que presumivelmente, possam dar conta da novidade. (SOLĖ; COLL, 1997, p. 19, 20).

Enfim, o referencial construtivista delineia um novo olhar para o processo de alfabetização, sobretudo considera que a criança tem conhecimentos prévios e, quando lhe é possibilitada, constrói e reconstrói a linguagem escrita. Contudo, esse sujeito precisa interagir com a cultura escrita e, para isso, o papel do professor é essencial para planejar um ambiente favorável para que ocorra uma aprendizagem significativa.

\section{Educação Não Formal e a Pedagogia Hospi- talar: Contribuindo no processo de aprendiza- gem de crianças hospitalizadas}

A educação não formal é uma modalidade de educação que transcende os muros da escola, ela perpassa por outros ambientes, ampliando a visão de educação, pois não podemos mais pensar a escola como único espaço educativo.

A luz dos estudos de Gohn (2008) a educação não formal atua em quatro dimensões: a primeira diz respeito à aprendizagem dos direitos do indivíduo como cidadão; a segunda se refere capacitar os indivíduos para o trabalho; a terceira consiste em uma aprendizagem voltada para a solução de problemas coletivos, ou seja, é uma aprendizagem que visa à organização dos indivíduos para realizar ações em prol da comunidade; a quarta diz respeito à aprendizagem de conteúdos escolares ministrados de forma diferenciada em espaços alternativos, como exemplo, os hospitais que trabalham com a pedagogia hospitalar, classes hospitalares ou ainda a hospitalização escolarizada. Esse campo da educação não formal torna efetivo o termo educação para todos no sentido de que as crianças hospitalizadas, até então, não tinham o direito legalmente sancionado para dar continuidade ao seu processo de aprendizagem. Ou seja, a visão restrita de educação deixa à margem as crianças em idade escolar que estão fora do espaço formal de ensino, por algum motivo, como por exemplo, as hospitalizadas, eis a importância da educação não formal chegando aos espaços hospitalares, mas ainda não é uma realidade em todo país.

De acordo com Matos e Mugiatti (2007, p. 21) ainda encontramos hospitais frios e temerosos tanto para as crianças como para os adolescentes, "há ainda que se considerar que os procedimentos conservadores da 
maioria dos hospitais sempre contribuíram, e ainda hoje contribuem, para que a sua realidade se mostre fria, impessoal e impregnada de carência de afetividade".

Esses espaços hospitalares frios refletem sérias conseqüências para as crianças que precisam ser internadas por um longo tempo, haja vista ela é bruscamente tirada do seu ambiente familiar e escolar. Para Matos e Mugiatti (2007, p. 26) essa situação suscita "sérios prejuízos ao desenvolvimento da criança/adolescente, no seu todo, e a recuperação integral tão zelosamente pretendida pelas equipes especializadas".

Diante disto, a hospitalização pode ocasionar danos no desenvolvimento cognitivo do educando, visto que durante a infância e adolescência tanto a criança quanto o adolescente estão construindo e reconstruindo saberes no espaço escolar. Então, a ruptura dessa rotina escolar produz desconfortos que vão prejudicá-los na sua volta para a escola e quiçá pode até motivar o afastamento definitivo da mesma.

[...] a criança e o adolescente, nessa fase, se encontram em pleno período de aprendizagem, que estão eles ávidos por novidades, essas operadas pela observação, experiência e comunicação-elementos constitutivos da aprendizagem em condições permanentes. (MATOS, MUGIATTI, 2007, p.28).

Essas são algumas considerações, importantes sobre a ruptura do processo escolar em virtude de uma hospitalização. Ou seja, a criança é excluída do direito de aprender. Legalmente essa situação inicia um processo de mudanças, pois em 1995, o MEC - Ministério da Educação, estabelece através da resolução $41 / 95$, 'Os Direitos da Criança Hospitalizada' dentre eles encontra-se no inciso 9: "Direito de desfrutar de alguma forma de recreação, programas de educação para a saúde, acompanhamento do curriculum escolar durante sua permanência hospitalar". (BRASIL, 1995, p.01)

Sendo assim, torna-se necessário rever as antigas práticas hospitalares que centravam-se somente nos aspectos biológicos do educando hospitalizado. A criança precisa de um atendimento integral biológico, social, psicológico e pedagógico. A dimensão pedagógica é defendida pelo Ministério da Educação por meio do do- cumento Classe hospitalar e Atendimento Pedagógico Domiciliar: estratégias e orientações, a fim de promover o atendimento pedagógico em ambientes hospitalares assim como domiciliares. Neste, o MEC define o termo classe hospitalar, a saber:

Denomina-se classe hospitalar o atendimento
pedagógico-educacional que ocorre em ambien-
tes de tratamento de saúde, seja na circunstância
de internação, como tradicionalmente conhecida,
seja na circunstância do atendimento em hospital-
-dia e hospital-semana ou em serviços de atenção
integral à saúde mental. (BRASIL, 2002, p. 13).

Esse documento conta com um aparato legal que assegura a obrigatoriedade do atendimento pedagógico hospitalar, mas conforme o MEC "são 850 hospitais oferecendo o atendimento, em um universo de quase $8 \mathrm{mil}$ unidades". (BIBIANO, 2009, p.81).

Diante desse panorama, a educação não formal está adentrando ao contexto hospitalar através da Pedagogia Hospitalar. Segundo as autoras Matos e Mugiatti, a Pedagogia Hospitalar é um atendimento pedagógico em ambiente hospitalar que transcende as perspectivas trabalhadas na escola.

[...] é um processo alternativo de educação continuada que ultrapassa o contexto formal da escola, pois levanta parâmetros para o atendimento de necessidades especiais transitórias do educando, em ambiente hospitalar e/ou domiciliar. Trata-se de uma nova realidade multi/ inter/transdiciplinar com características educativas. (MATOS; MUGIATTI, 2007, p.37).

Diante deste contexto, é necessário destacar a relevância do papel do pedagogo no ambiente hospitalar para a efetivação da Pedagogia Hospitalar. A sua presença vai além da transmissão de conteúdos.

[...] o pedagogo é agente de mudanças, pois entende-se que o escolar hospitalizado não é um escolar comum, ele se diferencia por estar acometido de moléstia ou algum dano ao seu corpo, razão pela qual precisou de cuidados médicos, bem como necessita ainda de ajuda para vencer as conseqüências de sua própria hospitalização. (MATOS; MUGIATTI, 2007, p. 73) 
Entretanto, cabe ressaltar que a intervenção do pedagogo deve estar alicerçada em uma proposta que vise à comunicação e o diálogo. São estratégias fundamentais para a criança se expressar nesse momento de aflição.

Além das dimensões biológicas e psicológicas da criança que precisam ser vistas no ambiente hospitalar, Ceccim (1999) defende outra questão crucial para a criança que se encontra hospitalizada, a escuta pedagógica, a qual ele denomina de "dimensão vivencial".

Essa dimensão conta-nos das expectativas de cura, sobrevida e qualidade de vida afetiva, de retorno às atividades anteriores e de continuidade dos laços com o cotidiano. Assim, a inclusão do atendimento pedagógico na atenção hospitalar, inclusive no que se refere à escolarização, vem interferir nessa dimensão vivencial porque resgata aspectos de saúde mantidos, mesmo em face da doença, enquanto respeita e valoriza os processos afetivos e cognitivos de construção de uma inteligência de si, de uma inteligência do mundo, de uma inteligência do estar no mundo e inventar seus problemas e soluções. (CECCIM, 1999, p.42)

Essa dimensão favorece o resgate da rotina da criança, haja vista ela vai vivenciar situações no ambiente hospitalar pertinentes a sua vida social antes da doença. Ou seja, a escuta pedagógica permite a criança, mesmo em um ambiente hospitalar continuar o seu processo de alfabetização, a conviver com o outro e interagir com a professora. Estes são os benefícios de um acompanhamento pedagógico e escolar. Conforme Fonseca (2008, p.15) essa dimensão não pode ser menosprezada é necessário que "de fato se escute o que o aluno tem a dizer."

Freire (1996, p. 119) concebe a escuta como um meio para conhecer e respeitar as diferenças. Essa escuta "significa a disponibilidade permanente por parte do sujeito que escuta para a abertura à fala do outro, ao gesto do outro, às diferenças do outro".

A pedagogia hospitalar é o reflexo da educação não formal em contexto hospitalar, pois ela é intencional, preconiza a continuidade do processo de aprendizagem, assim como resgata a vivência da criança antes da doença.
Ou seja, ela contempla uma das dimensões dessa modalidade educativa que visa à aprendizagem de conteúdos escolares em espaços alternativos.

Ademais, um campo da educação não formal é a alfabetização em espaços não escolares, logo o atendimento pedagógico educacional em hospitais contribui também no processo de alfabetização de crianças hospitalizadas, principalmente se as internações são longas. Acreditamos que a função da Pedagogia Hospitalar é resgatar toda a complexidade da criança e do adolescente que é bruscamente rompida pela doença e assim amenizar o sofrimento e recuperar a sua autoestima e promover o seu desenvolvimento cognitivo. Portanto, cabe ao pedagogo a responsabilidade de realizar atividades que façam a criança perceber que apesar do problema de saúde vivido naquele momento, é capaz de realizar muitas atividades interessantes, obviamente respeitando as suas limitações.

\section{Alfabetização em Contexto Hospitalar: Uma experiência no Hospital Universitário Materno Infantil}

A escolha do campo de pesquisa foi motivada pela experiência que tivemos com o Estágio de Séries Iniciais do curso de Pedagogia da Universidade Federal do Maranhão realizado no Hospital Materno Infantil. Durante o estágio observamos um contingente significativo de crianças que estavam na fase de alfabetização. Vale ressaltar que encontramos uma criança com oito anos que somente no hospital estava vivenciando esse processo. Isto desencadeou a necessidade de pesquisarmos como os responsáveis pelo atendimento pedagógico da instituição estavam trabalhando a linguagem escrita com as crianças que estavam na faixa etária correspondente à alfabetização.

Diante disto, decidimos realizar um Estudo de Caso para analisarmos como a Pedagogia Hospitalar desenvolvida no Hospital Universitário Materno Infantil tem contribuído para a criança hospitalizada evoluir no seu processo de alfabetização. Ou seja, quais as metodologias, recursos, concepções e estratégias estão sendo 
utilizadas pela pedagoga da instituição, a bolsista e voluntárias do projeto "Estudar uma ação saudável: construindo uma pedagogia hospitalar" para a realização de um trabalho que promova a interação da criança com o mundo da leitura e escrita.

Tanto a bolsista, quanto as voluntárias são alunas do curso de Pedagogia da Universidade Federal do Maranhão, estão atuando há um ano no projeto. É necessário ressaltar que a bolsista já tem experiência em alfabetização e já está a 02 anos no projeto. Quanto a pedagoga, é formada em Pedagogia está atuando no atendimento pedagógico do hospital desde 2005.

A Unidade Materno Infantil é integrada ao Hospital Universitário Presidente Dutra em São Luís Maranhão, com internação em média de 35 crianças. A instituição conta com 204 leitos. Suas especialidades são Pediatria, Cirurgia Pediátrica, Neonatologia, Obstetrícia e Ginecologia. Dispõe de uma sala interdisciplinar, localizada no quarto andar do hospital em virtude da pediatria clínica e enfermarias. Nessa sala são realizadas atividades lúdicas com crianças em diversas faixas etárias.

É necessário salientar que o trabalho desenvolvido pelos sujeitos da pesquisa vai além da sala interdisciplinar, porquanto o trabalho destas é realizado também nas enfermarias com as crianças e adolescentes que por motivos diversos não podem deixar seus leitos.

Através da aplicação de questionários e observação possibilitou analisar como a pedagogia hospitalar desenvolvida no HUMI tem contribuído para dar continuidade no processo de alfabetização das crianças hospitalizadas.

O ambiente hospitalar, assim como a sala de aula é heterogêneo, encontramos saberes diferenciados. Diante desse contexto, os sujeitos da pesquisa buscam conhecer o histórico escolar da criança hospitalizada, para isso realizam uma sondagem com os pais, após esse momento desenvolvem atividades de escrita e leitura para analisar o período de escrita da criança. A partir desse diagnóstico registrado em fichas, ocorre o planejamento das atividades que contempla o desenvolvimento da escrita para o período seguinte.
A metodologia enceta a partir da leitura de textos, considerando o conhecimento prévio das crianças através da participação, respeitando as suas hipóteses e suas limitações. Cabe ressaltar que a leitura é trabalhada através da ludicidade. Essa metodologia realizada dar oportunidades da criança ler e escrever, mesmo que ainda não leia e escreva convencionalmente. Segundo Teberosky e Colomer (2003), a leitura é a preparação para as próximas atividades que irão ser desenvolvidas posteriormente. Ademais, a leitura de histórias estimula nas crianças aspectos positivos como:

[...] aprendem a esperar mais tempo até ter sua vez de interagir, reconhecem a linguagem narrativa e podem até reproduzir a história que escutaram, fazem predições sobre a continuação da história, aprendem a prestar atenção, adquirem conceitos sobre o que está impresso, e imitam o modelo de leitura do adulto. (TEBEROSKY; COLOMER, 2003, p.24).

Quanto aos recursos os mais utilizados pelos sujeitos da pesquisa para desenvolver a sua metodologia tanto na classe interdisciplinar, assim como nos leitos são os textos, alfabeto móvel e jogos.

Acerca dessas informações, observamos que os recursos são pertinentes para trabalhar com crianças que estão no processo de alfabetização principalmente a utilização de textos, segundo os estudos de Teberosky e Colomer (2003, p.85) "para entrar no mundo da escrita é importante que as crianças interajam com uma grande diversidade de textos, já que são capazes de produzir e reproduzir textos narrativos, descritivos, de ficção, cartazes e textos de jornais etc.."

Com o alfabeto móvel os sujeitos da pesquisa estimula a criança pensar sobre a escrita, já que esta pode ler uma palavra e perceber que ainda faltam letras ou estar sobrando letras, de acordo com a sua hipótese. Esse recurso é indispensável para trabalhar a escrita nos leitos, uma vez que nas enfermarias não há os recursos que existem na sala interdisciplinar, por exemplo, o quadro branco, mesas para escrever. Durante a observação ficou evidente a predisposição das crianças em participar das atividades. Pois, uma criança foi um exemplo de superação mesmo com todas as difi- 
culdades, inclusive motora, ainda assim ela realizou a atividade com o alfabeto móvel. Nesse momento sentimos a alegria pela conquista tanto da criança, quanto do pai que estava acompanhando.

Outro recurso relevante são textos do tipo receituário e bula mencionado, uma vez que, estes fazem parte do contexto da criança no âmbito hospitalar. Trabalhar a leitura e a escrita com essa tipologia textual favorece ao educando a apreensão da função social destes textos e ao mesmo tempo a criança se apropria de informações importantes para a sua saúde através da língua escrita.

Os jogos são válidos, porque possibilita a criança refletir, levantar hipótese e ainda fomentam momentos de socialização e interação com outro, tão importante quanto à aprendizagem em âmbito hospitalar. Esses momentos proporcionam o resgate da vivência da criança.

Quanto à concepção de alfabetização compreendemos que todos os sujeitos da pesquisa acreditam na concepção de alfabetização que concebe a criança como um ser criador, ativo, que pensa, levanta hipótese para ler e escrever, além disso, acreditam que o objetivo da alfabetização é desvelar a função da língua escrita na prática social do discente, ou seja, percebemos um olhar construtivista, que concebe uma aprendizagem significativa. Segundo Curto, Morillo e Teixidó (2000, p. 84):

A vantagem da aprendizagem significativa é que permite pensar. Desenvolver e expressar as suas próprias idéias discutí-las, confrontá-las, melhorá-las, ampliá-las. Partir dessas idéias pessoais, dos conhecimentos prévios, do que já se sabe, pô-lo em movimento e atacar um problema novo e estimulante.

No que diz respeito à leitura desenvolvida nos leitos é trabalhada a interação da criança com o texto, ou seja, existe o cuidado de inserir o sujeito no mundo da leitura. Além de oferecer atividades de interpretação de texto e também de escrita. As atividades são planejadas para estimular o interesse da criança pela leitura, através da imaginação com riqueza de recursos. Consoante o olhar de Solé (1998, p.63):

[...] a riqueza de recursos sempre deve ser bem recebida, porém me parece que o que mais motiva as crianças a ler e a escrever é ver os adultos que tenham importância para elas lendo e escrevendo, assistir a leitura em grupos pequenos ou grandes, tentar e sentir-se aprovadas em suas tentativas.

Essa motivação defendida por Solé (1998) é notado nas respostas das voluntárias e da bolsista, pois através desse trabalho elas estão incitando nas crianças o interesse pela leitura, e principalmente fomentando a ampliação do vocabulário e a compreensão da função da cultura escrita. Quanto mais o professor diversificar os textos para realizar a leitura, mais oportunidades a criança terá de compreender os objetivos da leitura visto que realizamos a leitura para entreter, adquirir conhecimento, informação, seguir instruções etc.

Cabe ressaltar que não seria possível o atendimento de todas as crianças somente com trabalho da pedagoga do hospital. Nesse caso, essa parceria está refletindo bons frutos no aprendizado dos discentes hospitalizados, mormente quando se trata das crianças em idade de alfabetização que estão ávidas por leitura e escrita. Cada evolução no aprendizado é uma conquista que se transforma em estímulo para voltar para a sua rotina escolar. Essa sensação vivida no hospital eleva a autoestima e não deixa a criança ociosa.

[...] propõe-se a uma ajuda eficaz - a pedagógica - que pode ser dirigida ao enfermo, isto é, se as suas condições de enfermidade o permitirem, mesmo que em um ambiente diferenciado, o que se constitui em motivação para a continuidade de sua vida na sociedade. (MATOS; MUGIATTI, 2007, p.46).

Acreditamos que o atendimento pedagógico na instituição pesquisada revela a alegria e a vontade das crianças em participar das atividades desenvolvidas tanto na sala interdisciplinar assim como nos leitos. 


\section{Consideraçoes Finais}

Consideramos este estudo importante para salientar a nossa depreensão da relevância da educação não formal na vida de uma pessoa que por algum motivo não pode está na escola formal, principalmente quando nos referimos a uma criança que está construindo seus conhecimentos sobre a linguagem escrita e que, em virtude de uma enfermidade é afastada do seu ambiente social e do mundo da leitura e da escrita.

Graças à educação não formal que tem a finalidade de oportunizar situações de educação em contextos não escolares, o cenário do hospital está sofrendo transformações através da Pedagogia Hospitalar. É possível a criança hospitalizada continuar ou iniciar o seu processo de alfabetização no cenário diferente da escola, no caso, o hospital. Dessa forma, dando continuidade ao seu processo de aprendizagem, contribuindo assim para a sua autoestima e o seu desenvolvimento cognitivo, pois esse ambiente construído pela pedagogia hospitalar proporciona a escuta, o diálogo, a socialização e o aprendizado.

Diante desse ponto de vista, podemos concluir que no Hospital Universitário Materno Infantil está sendo construída uma pedagogia hospitalar que se preocupa em promover a continuidade do processo de alfabetização das crianças hospitalizadas, respeitando as suas limitações e corroborando a leis que discorrem do direito de estudar, independe do estado de saúde do educando.

Ademais, cabe ressaltar que a pedagogia hospitalar que está sendo construída tem uma ótica diferente do sujeito hospitalizado, não como paciente, mas como um sujeito cognoscente.

De acordo com análise de dados compreendemos que Pedagogia hospitalar tem contribuído no processo de alfabetização de crianças hospitalizadas. Pois, a prática alfabetizadora dos sujeitos da pesquisa está alicerçada na concepção de alfabetização que concebe a criança como um ser que pensa que constrói e reconstrói conhecimento. Acredita que o processo é desencadeado com textos e portadores de textos que vinculam a prática social.
Diante deste contexto, a metodologia busca despertar o interesse da criança através da participação nas leituras e escritas. Esse momento juntamente com as bolsistas, voluntárias, pedagoga e colegas hospitalizados é o resgate da vivência do educando hospitalizado, sobretudo a socialização. Essa situação constitui uma oportunidade da criança se expressar, usar o imaginário por meio da leitura, isto é, a criança precisa vivenciar essas situações para se sentir importante e compreender que é capaz de realizar atividades que estavam presentes na sua rotina antes da hospitalização. Os recursos são de uso social da língua escrita, lúdicos para estimular a interação com a cultura escrita.

Contudo, existem muitas dificuldades, desde a estrutura da sala interdisciplinar até mesmo construir uma práxis pedagógica diante de uma nova dimensão educacional, ainda pouco divulgada nos meios acadêmicos e por estudiosos da temática. Sendo assim, ainda existem muitos empecilhos no caminho da pedagogia hospitalar, todavia existe a esperança e a vontade de realizar um trabaIho diferenciado na instituição com crianças que estão no processo de alfabetização.

Enfim, o atendimento pedagógico na instituição pesquisada revela a alegria e a vontade das crianças em participar das atividades desenvolvidas tanto na sala interdisciplinar, assim como nos leitos. Sendo assim, as atividades pedagógicas desenvolvidas em âmbito hospitalar, propicia a evolução no processo de alfabetização, contribuindo para o regresso da criança a sua rotina após a hospitalização, ou seja, o retorno ao seio da família, escola, amigos, professora.

\section{Referências}

BIBIANO, Bianca. Ensino nas horas difíceis. Nova Escola, São Paulo, ano XXIV, n.220, p. 81-83, mar. 2009.

BRASIL. Resolução no 41. Direitos da criança e do adolescente hospitalizados. CONANDA. Diário Oficial da União, Brasília, DF, 17 out. Seção I, p.16319-16320, 1995.

- Classe hospitalar e atendimento pedagógico domiciliar: estratégias e orientações. Brasília: MEC; SEESP, 2002.

CARRETERO, Mario. Construtivismo e Educação. Tradução de Jussara Haubert Rodrigues, Porto Alegre: Artes Médicas, 1997. 
CECCIM, Ricardo Burg. Classe hospitalar: encontros da educação da saúde no ambiente hospitalar. Revista Pátio, Porto Alegre, ano III, no 10, p.41-44, ago/out. 1999.

CURTO, Lluís Maruny; MORILLO, Maribel Ministral; TEIXIDÓ, Manuel Miralles. Escrever e ler: como as crianças aprendem e como o professor pode ensiná-las a escrever e a ler. Porto Alegre: Artmed, 2000.

FERREIRO, Emilia. Atualidades de Jean Piaget.. Tradução de Ernani Rosa, Porto Alegre: Artmed, 2001 a.

. Reflexões sobre alfabetização. 24 ed. São Paulo: Cortez, 2001b.

. Com todas as letras. 13 ed. Tradução de Maria Zilda da Cunha Lopes. São Paulo: Cortez, 2005.

FONSECA, Eneida Simões da. Atendimento escolar no ambiente hospitalar. 2. Ed. São Paulo: Memnon, 2008.

FREIRE, Paulo. Pedagogia do oprimido. 46. ed. Rio de Janeiro: Paz e Terra, 1996

GOHN, Maria da Glória. Educação não-formal e cultura política: impactos sobre o associativismo do terceiro setor. 4 ed. São Paulo: Cortez, 2008.

MATOS, Moreira Lucia; MUGIATTI, Margarida Maria Teixeira de Freitas. Pedagogia hospitalar: a humanização integrando educação e saúde. 2 ed. Petrópolis, Rj: Vozes, 2007.

SOLÉ, Isabel. Estratégias de leitura. 6. ed. Porto Alegre: Artmed, 1998.

TEBEROSKY, Ana; COLOMER, Tereza. A aprender a ler e a escrever: uma proposta construtivista. Porto Alegre: Artmed, 2003. 
